DOI: $10.15838 / \mathrm{esc} / 2016.5 .47 .11$

(C) Oeij P. R.A., Dhondt S., Žiauberytė-Jakštienè R., Corral A., Totterdill P.

\title{
Implementing Workplace Innovation across Europe: Why, How and What?
}

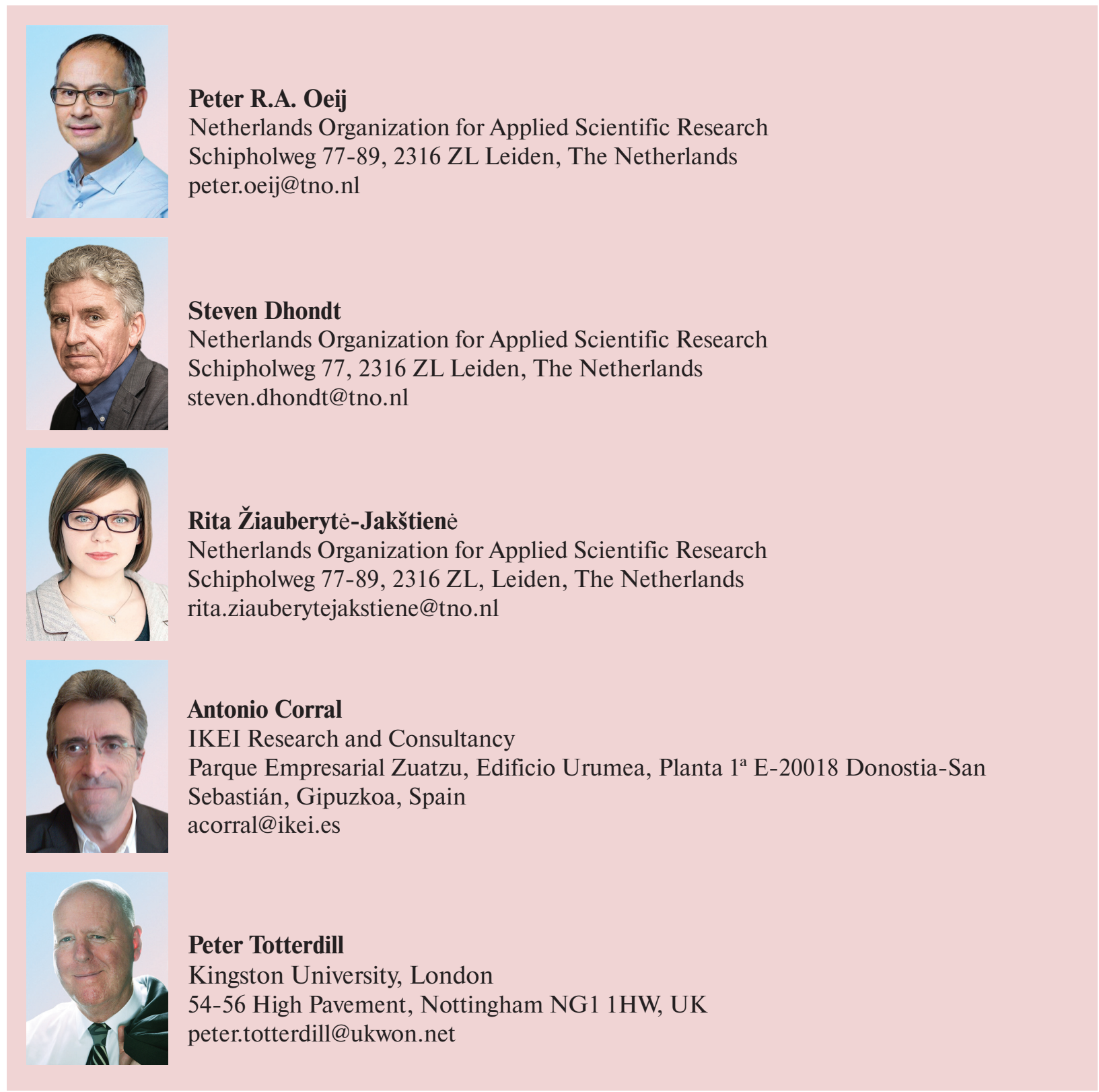

For citation: Oeij P. R.A., Dhondt S., Žiauberytė-Jakštienè R., Corral A., Totterdill P. Implementing workplace innovation across Europe: Why, How and What? Economic and Social Changes: Facts, Trends, Forecast, 2016, no. 5, pp. 195-218. DOI: $10.15838 / \mathrm{esc} / 2016.5 .47 .11$ 


\begin{abstract}
Based on a 51-case study research in 10 EU Member States this article demonstrates the implementation of workplace innovation. Why do companies apply workplace innovation and what different strategies can be discerned? How do these companies implement workplace innovation interventions and who are involved in that process? Finally, what types of workplace innovation interventions are being implemented, and what is known about the (expected) effects. The article concludes that successful workplace innovation is interplay of management driven business goals and employee driven quality of work goals. The implication for both companies and policy makers is that constructive cooperation between management and employees is a key success factor for innovation, competitiveness and active jobs. We close by providing policy makers and practitioners with a few suggestions to improve the dissemination and implementation of workplace innovation respectively.
\end{abstract}

Key words: workplace innovation, implementation, European Union, European Company Survey.

\section{Introduction}

\subsection{Why should companies implement} workplace innovation?

The immediate answer to why companies should adopt and implement workplace innovation (WPI) is that it is beneficial for both business performance and the quality of jobs. But there is more than 'nice to have'. The need of workplace innovation arises from ongoing change and the urgency to compete or function efficiently, against the growing experience that technological and business (model) innovation alone are insufficient to face today's demands. A combination of clever organizing and applying human talents in smarter ways is what is asked for, as a 'need to have'.

Pot and colleagues (2011; Pot, Dhondt \& Oeij, 2012 and Pot, Totterdill \& Dhondt, 2016) sketched develop- ments over time in European countries that carried out national innovation programmes to combat declining economic growth, employment and competitiveness. The background of these programmes is the understanding that competitiveness is not realised through merely stimulating new technological developments and costcutting efficiency policies. In order to realise sustainable economic growth and welfare provision continuous innovation and growth in productivity is needed. According to Pot, there are several reasons for the emerging attention to workplace development (Pot et al, 2012). First, there is the need to enhance labour productivity to maintain our level of welfare and social security. Second, the need to develop and utilise the skills and competences of the potential workforce to increase 
added value is crucial. Third, to fully benefit from technological innovation, this needs to be embedded in workplace innovation, i.e. making technology work by means of proper organising. Fourth, workplace innovation itself appears to associate positively with innovation success, namely innovation in general.

Redesigning organisations and work processes matter for performance and jobs in general (e.g., Bloom \& van Reenen 2010; Boxall, 2012; Boxall \& Macky, 2009), but what does the evidence say about workplace innovation? The benefits of WPI have been documented for both individual employees and organizations and in a range of organizational and national contexts. For example, WPI has been linked to both improved individual level outcomes such as indices of quality of working life and also improved organizational performance (Ramstad, 2009; Eeckelaert, Dhondt, Oeij, Pot et al, 2012), quality of working life (Kalmi \& Kauhanen, 2008), better organisational performance as a result of implementing WPI (Dhondt \& van Hootegem, 2015; Oeij, Dhondt \& Korver, 2011; Oeij \& Vaas, 2016), and applicability in SMEs (Oeij, de Vroome, Bolland, Gründemann, \& van Teeffelen, 2014). A recent Eurofound report gives strong indications that the presence of WPI practices associate with better organisational performance and employee engagement. Moreover, companies used different paths to arrive at becoming a WPI-mature organisation according to this report, meaning they applied different combinations of WPI-practices and stressed different organisational choices (Oeij, Žiauberytė-Jakštienè, Dhondt, Corral et al, 2015a). The findings underline the idea that organising can be used as a strategic tool to induce not only higher performance, but also better quality of work (Pot, 2011, also see Chapter 3 of this volume). Workplace innovation can lead to more 'active jobs' as a purposive form of work organisation, which could be characterised as 'complex jobs' - which are rich and meaningful - in 'simple organisations' - which are clear in management structure, division of labour and transparent responsibilities (de Sitter, den Hertog \& Dankbaar, 1997). Organisations can choose production systems that enable these results, like flow structures and teams (Achterbergh \& Vriens, 2010: 227280; Christis, 2010), which implies that WPI is related to organisational changes at the 'root cause' of the production process of making products and delivering services (MacDuffie, 1997). Workplace innovation, however, 
is a slippery concept (European Commission, August 2014), that needs some theoretical boundary setting, as we try to do in the next section.

\subsection{Definition}

The applied definition of workplace innovation practices is: a developed and implemented practice or combination of practices that structurally (division of labour) and/or culturally (empowerment) enable employees to participate in organisational change and renewal to improve quality of working life and organisational performance (Oeij et al, 2015a: 8, 14).

This conceptualisation of WPI implies that one needs to look at the organization as a whole and consider the reciprocal effects of strategy, structure and culture, if they are to reap the benefits associated with WPI (Howaldt, Oeij, Dhondt \& Fruytier, 2016). For instance, hierarchical organisational structures may lead to more directive leadership styles and Human Resource Management (HRM) practices that focus on a clear division of labour and control, whereas less hierarchical structures may lead to leadership styles and HRM practices that are geared at promoting employee involvement, engagement and commitment (MacDuffie, 1997; Pot, 2011 more on the relationship between HRM and WPI in Chapter 3 and 13 in this volume). Therefore, to fully understand WPI, it might be fruitful to not only focus on certain types of HRM practices and their consequences, but to also take into consideration the organisational structure and the management philosophy underlying strategic choices. Too often WPI is narrowed down as an 'HR-toy'. As a consequence, decision makers on technological innovation, business model innovation and marketing innovation underestimate and underuse the potential of workplace innovation (Dhondt \& Oeij, September 2014), as they are largely unaware of the role of organisation and people to make non-technical innovations a success. Within organisations HR-managers and line- and operational managers too strongly function within separate silos (Howaldt et al, 2016).

The workplace innovation's 'structure orientation' contains practices that structure work organisation and job design (Oeij et al, 2015a; de Sitter et al, 1997). As described, these practices concern the division of labour, the division of controlling ('managing') and executing tasks, and provide employees with structural decision latitude or control capacity (Dhondt, Pot \& Kraan, 2014). Such an approach goes beyond HR-dominated streams (such as High Performance 
Work Practices and High Involvement Work Practices), as its root causes lie in the choices made about how to design the production system. Structure-oriented practices can stimulate employee-control or autonomy, and provide a ground for voice of employees (and employee representatives).

The workplace innovation's 'culture orientation' contains practices that provide opportunities for employees to participate in various ways, for example, in organisational decision-making (Oeij et al, 2015a). It not only concerns employees, but it could include employee representatives as well, as in the case of social dialogue and collective bargaining. Cultureoriented practices can stimulate commitment and provide employees (and employee representatives) with voice (Totterdill \& Exton, 2014). Not merely in the meaning of contracts and pay for performance, but also including psychological rewards, such as appreciation, recognition and professional acknowledgement.

\subsection{Introducing the Eurofound study}

The Eurofound study 'Workplace innovation in European companies' (Oeij et al, 2015a, Oeij, ŽiauberytèJakštienè, Dhondt, Corral et al, 2015b) is a case study of 51 companies from 10
EU Member States, according to the following regional breakdown:

- Continental and Western Europe - Denmark, Germany, Ireland, the Netherlands, United Kingdom

- Southern Europe - Greece, Spain

- Central and Eastern Europe Bulgaria, Lithuania, Poland

The sampling of countries was based on the purpose to achieve a certain degree of variation in WPI across Europe - and is based on the wider regional grouping (seven groups) employed in earlier reports on work organization by Eurofound, 2013. The aim of the sampling was to ensure variation in terms of context, culture, institutions and entrepreneurial behaviour.

The purpose of the research was to explore why and how companies apply WPI, and what were the impacts for the organisation and for the employees. Another goal was to demarcate WPI as a theoretical concept in order to contribute to a better understanding of WPI and building on common agreement of WPI. A final target was to offer policy makers in Europe recommendations how to further pursue and stimulate WPI across Europe. The companies were selected from the European 
Company Survey 2013 (ECS-survey) database comprising about 30.000 companies (Eurofound, 2015). For this purpose a WPI-index score was constructed to rank all companies in terms of their WPI-features, which could be calculated from present indicators (survey items) of the ECSquestionnaire $^{1}$ (Dhondt, Preenen, Oeij, Corral et al, February 2014; Oeij et al, 2015b). This enabled us to select those companies from the top $5 \%$ of the ranking of WPI-index scores. Therefore each selected company is, compared to the majority of companies in the database, a relatively 'good example' of a WPI-company. This means that, according to the ECS-survey data, these companies are rather active or rather mature in terms of WPI-features.

The final cases were selected through direct contacts with the companies explaining the purposes of the project. In the end, the cases retained come from a variety of European regions,

The WPI-Index score (Oeij et al, 2015b) is constructed of separate items derived from the ECS Management Questionnaire, which are connected to the theory of high performance work systems. Use of Principal Component Analysis (PCA, factor analysis, applying varimax rotation) resulted in a latent structure in the data consisting of seven factors:1) innovation (product and organisational innovation), 2 ) voice (employees /employee representatives having a say in decisions and changes), 3) learning and reflection (training and feedback), 4) structure and system (variable pay), 5) work organisation autonomy (autonomy), 6) work organisation career (long-term career plans), 7) hierarchy. The WPI-Index score was calculated as the sum score of these separate factors, implying that each of these elements was given the same weight in the WPI-index. operating in different sectors, having distinct products and services, and varying in size:

- company size: SMEs with between 50 and 249 employees ( 27 companies) and large companies with 250 employees or more (24 companies);

- branch: industry (comprising manufacturing, construction, pharmaceuticals, energy, agro-business -21 companies); commercial services (comprising retail, finance information, consultancy, transport, waste management, hotels - 14 companies); social services (comprising education, social work, arts, administrative, testing, science, journalism, libraries - 16 companies).

- Country Continental and western Europe - Denmark, Germany, Ireland, the Netherlands, UK (22 companies); Mediterranean - Greece, Spain (12 companies); Central and eastern Europe - Bulgaria, Lithuania, Poland (17 companies).

In each company face-to-face or group interviews ${ }^{2}$ were intended with a manager, a group of employees, and employee representatives; these were always persons who were involved and knowledgeable of the WPI practices to

The interviews were done with a structured checklist by the interviewer; afterwards the interviewer imputed the answers of the interviewee into a pre-coded survey, the so-called coding matrix. The coding matrix contained quantitative and qualitative data. The quantitative data were used for statistical analysis (SPSS) and QCA analyses (Oeij et al, 2015b). 
be studied. However, for diverse reasons (usually operational difficulties during the field work), in five companies it was impossible to talk to employees and in 16 companies no employee representatives were available.

The fieldwork across the 10 countries mentioned above was carried out by nine European research institutes using a standardized methodology (Oeij et al, 2015b). All in all about 200 people were interviewed, following specific questionnaires for each interviewee category (in general, 3 questionnaires per firm). The information gathered was imputed into a data file (the 'coding matrix') and each case was described in a mini-case study report (2-3 pages) $)^{3}$. In each company, specific WPI practices were identified (up to 168 practices in total). Subsequently, using qualitative comparative analysis (QCA), the questionnaires were analysed, studying the 'conditions' within these companies that explain the presence of substantial WPI practices. These conditions together constitute 'configurational paths' that can be regarded as implicit strategies applied to be or become a WPI company. Case study reports were used to assess whether types of WPI practices

All cases can be found on the Eurofound website at: https://www.eurofound.europa.eu/workplace-innovation-ineuropean-companies-case-studies could be distinguished. Qualitative information from interviews was used to get a richer description of contextual factors, drivers and motivations, ways of developing and implementing WPI, and the impacts of WPI. It enabled an in-depth analysis of the companies and their WPI practices.

\subsection{Central question}

In this contribution our central question is how do companies implement WPI? To address this question we will pay attention to the process of the implementation of WPI. The role of participants in developing and implementing WPI is of main interest. In order to understand how the implementation takes place, it is relevant to know the reasons of participants why to start with WPI in the first place, and, also, to get a view on their expectations of the implementation of WPI. We will start with looking into why companies implement WPI.

\section{WPI implementation in practice}

2.1. Why do companies want to implement WPI?

To see why companies introduced WPI-practices a distinction was made between two drivers or targets, namely to improve the quality of performance of the organisation or to improve the quality of working life and employee engagement. The analysis of the 
Table 1. Types of practices applied and drivers (percentages)

\begin{tabular}{|c|c|c|c|c|c|c|c|}
\hline \multirow{3}{*}{ Drivers } & not HPWP & \multicolumn{4}{|c|}{ High Performance Work Practices (HPWP) } & \multirow{3}{*}{$\begin{array}{l}\bar{\Phi} \\
\bar{\Xi}\end{array}$} & \multirow{3}{*}{ 胥 } \\
\hline & \multicolumn{3}{|c|}{ WPI } & \multirow[b]{2}{*}{ Total WPI } & \multirow[b]{2}{*}{$\mathrm{HR}$} & & \\
\hline & WPI-structure & $\begin{array}{l}\text { WPI- } \\
\text { culture }\end{array}$ & WPI-mixed & & & & \\
\hline Quality of Performance & 1.8 & 1.2 & 3.6 & 6.5 & 3.6 & 3.6 & 13.7 \\
\hline Quality of Work & 3.0 & 3.6 & 4.2 & 10.7 & 6.5 & 0.6 & 17.9 \\
\hline $\begin{array}{l}\text { Both: Quality of Work and } \\
\text { Performance }\end{array}$ & 8.9 & 15.5 & 11.3 & 35.7 & 28.6 & 4.2 & 68.5 \\
\hline Total & 13.7 & 20.2 & 19.0 & 53.0 & 38.7 & 8.3 & 100.0 \\
\hline $\mathrm{N}$ & 23 & 34 & 32 & 89 & 65 & 14 & 168 \\
\hline
\end{tabular}

questionnaires completed in the case studies showed the existence of a third category as well that combined both drivers. Although economic reasons drive the decision to introduce WPI, most practices identified in the case studies (69\%) are eventually targeted to both goals, the enhancement of company's performance and quality of working life, while the remaining practices are approximately equally divided into those that focus on quality of working life (18\%) and quality of performance (14\%) (See Table 1).

Table 1 presents a total of 168 WPIpractices that where identified in the selected companies. Half of these practices (53\%) are either focusing on WPI-structure elements (14\%), WPIculture elements $(20 \%)$ or are a mixture of structure and culture practices $(19 \%)$. Quite a high proportion of practices are assessed as exclusively
HR-practices (39\%), which we see as too limited to qualify as a genuine WPI-practice. The practices in this category are 'typical' or 'traditional' $\mathrm{HR}$-practices in the field of, for example, personnel recruitment, training, competence development, performance appraisal, working conditions, remuneration, flexibility and health, risk and safety measures. The category 'other' (8\%) comprises examples of cost-effectiveness, efficiency improvement and ICTpractices that neither qualify as WPI.

The close reader of Table 1 will have noticed that WPI-practices partly overlap with High Performance Work Practices (HPWP): first, there is overlap with high-involvement work practices (HIWPs) regarding the structuring of work and jobs to enhance employee autonomy; second, WPI overlaps with high-commitment management 
(HCM) regarding 'culture' aspects, such as participatory employment relations and giving employees voice. WPI differs from HPWP in relation to 'traditional' HR practices, meaning HR measures that are not focusing on employee engagement and not on organisational design ('structure') (Oeij et al, 2015: 13-17).
Table 2 provides some concrete examples of the 168 practices identified. The complete list of practices (including HR-practices) can be found in the Annex to the report (Oeij et al, 2015b). The consequence of the fact that most WPI-practices are both directed at economic goals and better work, is that not only economic goals are

Table 2. Examples of WPI-practices

\begin{tabular}{|c|c|}
\hline Types of practices & Examples* \\
\hline \multirow[t]{4}{*}{$\begin{array}{l}\text { WPI: structure } \\
\text { orientation }\end{array}$} & $\begin{array}{l}\text { DE-SERV-TEST-L made a structural change of the organisation and workplaces lead to 'subject or theme related } \\
\text { teams' across the different departments. }\end{array}$ \\
\hline & $\begin{array}{l}\text { BG-EDUC-UNI-S: Self-managing teams is a system for organising day-to-day duties and activities. This } \\
\text { approach ensures that the team members will have sufficient flexibility to decide how to implement their tasks } \\
\text { taking into account their own capacities and time schedule. }\end{array}$ \\
\hline & $\begin{array}{l}\text { ES-SCI-ENVIRONM-L: Minimising organisational levels and enhancing autonomous teams is done by ensuring } \\
\text { that there are no more than two hierarchical levels between the lowest and the highest levels. This also facilitates } \\
\text { the existence of self-managed working teams that have the freedom to organise themselves. }\end{array}$ \\
\hline & $\begin{array}{l}\text { NL-INFO-NEWS-L: Job enlargement by expanding sales jobs with account management tasks; also cross } \\
\text { functional teams were installed to realise innovation projects across departments }\end{array}$ \\
\hline \multirow[t]{4}{*}{$\begin{array}{l}\text { WPI: culture } \\
\text { orientation }\end{array}$} & $\begin{array}{l}\text { DK-ART-MUSEUM-S: Partnership with unions. New projects and organisational changes are debated in a joint } \\
\text { committee with union representatives, OHS representatives and management representatives. This committee } \\
\text { is initiating new practices such as training and support for new employees. }\end{array}$ \\
\hline & $\begin{array}{l}\text { BG-ENER-GAS-S: The Knowledge Management System, OGpedia, is a voluntarily developed IT-based } \\
\text { information sharing measure. All employees can share and gain new knowledge. }\end{array}$ \\
\hline & $\begin{array}{l}\text { PL-ADM-TAX-S: Monthly meeting with managers and union representatives help to communicate changes and } \\
\text { current situation status, consult decisions and initiatives. }\end{array}$ \\
\hline & $\begin{array}{l}\text { LT-SERV-POST-L: "Loyalty Day" aims to enhance communication and knowledge sharing between managers } \\
\text { and first line workers. Managers voluntarily visit workers on their working site and gather information } \\
\text { about specific processes and possible issues. This raises sustainability, efficiency and good organisational } \\
\text { communication. }\end{array}$ \\
\hline \multirow[t]{3}{*}{ WPI: mixed } & $\begin{array}{l}\text { ES-SCI-WORK-L: Flexitime practices allow workers to have a say on their working times: they can adjust their } \\
\text { starting and exiting hours, also ad-hoc exits (with manager's permission) are allowed. }\end{array}$ \\
\hline & $\begin{array}{l}\text { EL-FIN-BANK-L: An initiative for personal development: every year teams of 1-2 people take part in a challenge } \\
\text { defined by the top leaders. In this way ideas can be passed from young talents to the top management. Young } \\
\text { talents are supported by coaching sessions and assessment tools, they gain experience. }\end{array}$ \\
\hline & $\begin{array}{l}\text { DE-AGRO-PETFOOD-S: Overall Competences: Ready to do any job in the production line, an overall qualification } \\
\text { was given to the production staff, enabling the employees to take over every job in the production. After the } \\
\text { mechanisation of production most of the employees had the chance to upskill and take over a skilled workers' } \\
\text { task. }\end{array}$ \\
\hline
\end{tabular}


achieved, but also more employee engagement and regularly a better quality of working life as well. Workplace innovators are almost naturally bonding with employee interest and there is an agreement among managers, employees and employee representatives on what has priority and what is less important, as we will show soon.

Comparing the drivers there is no difference between WPI-practices and $\mathrm{HR}$-practices. Interestingly, the HPWP-literature reports on the dominance of organisational performance goals as drivers (Boxall \& Macky, 2009). Possibly our sample of relatively high WPI-companies differs from most companies researched in that stream. Finally, although the category of 'other' practices is very small it seems to be more directed at organisational performance than at quality of working life.

Returning to the mentioning of different paths leading to becoming a mature WPI-company, all companies in their paths applied more than one WPI-practice, often a combination of structure oriented, culture oriented and HR-measures. This may be an indication that 'bundling' measures matters, as is proposed in the HPWPliterature. No conclusions about combinations of WPI-practices can be drawn, however, as there is quite some variety of WPI-practices within paths (Oeij et al, 2015a).

Now let us look closer at the motives, leverage factors and impacts of WPI, before we turn to the 'how' question. The opinions of managers, employees and employee representatives have been compared and much agreement was reported.

\subsection{What are reasons or motives to}

\section{implement WPI?}

Although companies did choose varying paths to WPI and selected different (combinations of) WPIpractices, the reasons why they initiate WPI conversely reflect much commonality. The analysis carried out (both quantitative and qualitative) show that there is a dominance of economic oriented motives (Table 3). However, many companies understand that achieving economic goals largely depends on the role that employees play, so that WPI appears as a precondition to reach other economic and managerial goals. In this sense, from the viewpoint of the 'organisation as a whole', the most prominent three general motives identified by the three groups of interviewees (managers, employees and employee representatives) for initiating a WPI implementation, were efficiency improvement, to gain competitive advantage and to enhance innovative capability. 
Table 3. General motives for the implementation of WPI

\begin{tabular}{|c|c|c|c|}
\hline Мотивы & Manager & $\begin{array}{c}\text { Group } \\
\text { of Employees }\end{array}$ & $\begin{array}{c}\text { Employee } \\
\text { Representatives }\end{array}$ \\
\hline & \multicolumn{3}{|c|}{ Percentage of companies } \\
\hline \multicolumn{4}{|l|}{...for the 'organisation as a whole' } \\
\hline To improve efficiency & 80 & 80 & 74 \\
\hline To gain competitive advantage & 78 & 58 & 65 \\
\hline To enhance innovative capability & 75 & 58 & 65 \\
\hline To become an attractive employer & 57 & 53 & 44 \\
\hline To enable the acceptance by employees & 37 & 31 & 47 \\
\hline To enable the embedment of new technology and ICT & 37 & 33 & 35 \\
\hline To improve industrial relations with unions & 18 & 9 & 47 \\
\hline \multicolumn{4}{|l|}{...from managers' and employees' perspective } \\
\hline Economic and business goals & 94 & 89 & 88 \\
\hline Learning and development opportunities & 78 & 71 & 74 \\
\hline Performance & 61 & 62 & 59 \\
\hline Public goals & 31 & 33 & 32 \\
\hline Flexibility & 31 & 42 & 38 \\
\hline Shareholder interests & 25 & 24 & 29 \\
\hline Labour market position & 25 & 18 & 35 \\
\hline Balance private-work life situation & 25 & 24 & 32 \\
\hline $\mathrm{N}$ of respondents & 51 & 45 & 34 \\
\hline
\end{tabular}

Apart from looking at motives for 'the organisation as a whole', the investigation of 'motives' was also approached as possibly desired impacts for each group of stakeholders separately (management, employees and employee representatives) (Table 3). It proved that motives for
WPI implementation from both the managers' and employees' perspectives overlap ${ }^{4}$, and, moreover, show resemblance with the general reasons to initiate $\mathrm{WPI}^{5}$. The three most salient motives are economic and business goals, learning and development opportunities, and performance.

\footnotetext{
$4 \mathrm{McNemar}$ test is a statistical test used on paired nominal data to determine whether the row and column marginal frequencies (matched pairs of subjects) are equal ("marginal homogeneity"). Results indicated that there are no significant differences in how frequently managers, employee groups and employee representatives selected the top-3 motives (economic and business goals, learning and development opportunities, performance).

5 All three groups indicated the improvement of efficiency as the most important motive for the "organization as a whole", while gaining competitive advantage and enhancing innovative capability were the second two most important motives. No differences were found among the three groups in the frequency of selecting the improvement of efficiency (McNemar tests nonsignificant, all $\mathrm{p}>.05$ ). Managers' selected gaining competitive advantage more often than groups of employees and employee representatives (respectively $\mathrm{p}=.049$ and $\mathrm{p}=.039$ ); managers also selected enhancing innovative capability more often than employee representatives $(\mathrm{p}=.039)$. Here and in further comparisons attention should be given to the multiple data missings among employee representatives $(>30 \%)$.
} 
Motives that are related to quality of organisational performance were regarded as more prominent than the ones related to quality of working life according to all three actor groups.

\subsection{What are important leverage} factors for the implementation of WPI?

Leverage factors are actions, measures or means that drive the successful implementation of WPIpractices. The most important three leverage factors for WPI implementation are employee involvement, top management commitment, and, at a distance, leadership or the involvement of a powerful person, as was reported by all three groups of interviewees (Table 4) ${ }^{6}$. While reasons and motives to start WPI point to business related arguments, employee involvement seems a sine qua non when it comes to adoption and implementation, as perceived by respondents.

Some examples (extracted from the case studies) of the top three leverage factors are presented in the following text box (Oeij et al, 2015a: 48).

1. Employee involvement

PL-EDUC-MED-SCHOOL-S had to create new curricula. Employees were the main force behind this change: they actively participated in sharing their knowledge and formalizing new programmes. The school started to actively participate in various external projects (related to other institutions), because of workers who were enthusiastic about new activities.

2. Top management commitment LT-SERV-POST-L initiated WPI practice ("Loyalty Day") that relies on management's willingness to

Table 4. Leverage factors for WPI implementation

\begin{tabular}{|l|c|c|c|}
\hline \multicolumn{1}{|c|}{ Factors } & Manager & $\begin{array}{c}\text { Group } \\
\text { of Employees }\end{array}$ & $\begin{array}{c}\text { Employee } \\
\text { Representatives }\end{array}$ \\
\hline & \multicolumn{3}{|c|}{ Percentage of companies } \\
\hline Employee involvement & 82 & 84 & 88 \\
\hline Top management commitment & 80 & 69 & 68 \\
\hline Leadership, powerful person & 67 & 56 & 65 \\
\hline Organisational, non-conflictive climate & 49 & 42 & 50 \\
\hline Resources, enough money and people & 33 & 38 & 29 \\
\hline Time, no interference from reorganisation & 18 & 20 & 24 \\
\hline N of respondents & 51 & 45 & 34 \\
\hline Source: Oeij et al, 2015b: 27. & & \\
\hline
\end{tabular}

6 McNemar test indicated that there are no significant differences in how frequently managers, employee groups and employee representatives selected the top-3 leverage factors (employee involvement, top management commitment, and leadership, powerful person). 
participate in the activity. Managers are expected to visit various companies' locations and get information from the front line workers. Since management paid attention and spent time on this activity, the company was able to learn from this practice.

3. Leadership, powerful person

UK-CONST-BUILD-L has been on a sustained journey of transformation since a new CEO appointment in 2009, distancing itself from traditional industry practices by embracing high ethical principles relating to safety, the environment, transparency and quality.

\subsection{What are the impacts or expected impact of WPI?}

Impacts of WPI-practices, like drivers, can be divided into effects for organisational performance and for the benefits of employees. Four types of impacts are researched: impacts for the organisation, for management, for employees, and for employee representatives. Table 5 presents the top three-to-five for each type.

Table 5. Impacts of WPI

\begin{tabular}{|c|c|c|c|}
\hline Impacts & Manager & $\begin{array}{l}\text { Group } \\
\text { of Employees }\end{array}$ & $\begin{array}{c}\text { Employee } \\
\text { Representatives }\end{array}$ \\
\hline & \multicolumn{3}{|c|}{ Percentage of companies } \\
\hline \multicolumn{4}{|l|}{ for the organisation } \\
\hline Employee engagement & 82 & 78 & 85 \\
\hline Longer term sustainability & 73 & 64 & 62 \\
\hline High performance & 67 & 56 & 59 \\
\hline Establishing good work & 63 & 47 & 62 \\
\hline \multicolumn{4}{|l|}{ for managers/managers' interests } \\
\hline Efficiency & 73 & 64 & 74 \\
\hline More sustainability & 71 & 60 & 62 \\
\hline Competitiveness & 65 & 53 & 59 \\
\hline Innovation/innovation capability & 61 & 47 & 59 \\
\hline Satisfied client, customer & 61 & 53 & 59 \\
\hline \multicolumn{4}{|l|}{ for employees/employees interests } \\
\hline Learning opportunities & 71 & 67 & 59 \\
\hline Voice, participation & 59 & 56 & 59 \\
\hline Challenging, active jobs & 57 & 64 & 44 \\
\hline Healthy work & 43 & 49 & 56 \\
\hline \multicolumn{4}{|c|}{ for employee representatives/union interests } \\
\hline Employees voice & 79 & 67 & 85 \\
\hline Sustainable organisation & 56 & 33 & 50 \\
\hline Equality, fairness & 35 & 33 & 41 \\
\hline
\end{tabular}


For the organisation, according to managers, employees and employee representatives, employee engagement was the most important outcome of WPI followed by long term sustainability ${ }^{7}$, and, with some distance high performance, better customer focus/client focus, efficiency, and profitability. For employee representatives notable outcomes were also the establishment of good work and more positive employment relations. Remarkable maybe, but according to employees establishing good work is ranked lower than efficiency, profitability and high performance (not visible in Table 5, see Oeij et al, 2015b; 28-29).

The most important impacts of WPI for 'managers interests' are efficiency and sustainability; for 'employees interests' are learning opportunities, voice/participation, and challenging and active jobs; and for 'employee representatives/union interests' is employee voice.

When we summarize why companies implement WPI, what they see as most important leverage factors, and which are the (expected) impacts of WPI for the organisation, managers, employees

\footnotetext{
McNemar test indicated that there are no significant differences in how frequently managers, employees and employee representatives selected the two top outcomes (employee engagement and longer term sustainability), so there is agreement among groups.
}

and employee representatives it becomes clear that there is much commonality in the answers from the three different respondent groups. Given that economic goals are triggering the initiation of WPI and that employee involvement is a key factor in the introduction of WPI, it is intriguing to see how much accord emerges when we look at the impacts for, respectively, the organisation, the managers' interest, the employees' interests and the employee representatives' interest.

All three actors regard:

- employee engagement (with a remarkable difference above any other factor), longer term sustainability and high performance as the most important impacts for the organisation;

- efficiency, more sustainability and competitiveness as the most important impacts for the managers;

- learning opportunities, voice/ participation and challenging and active jobs as the most important impacts for employees;

- employees voice as the most important impact for employee representatives.

In the process of introducing the WPI-practices in many instances, the eventual impacts both improve the economic performance, employee engagement and quality of working life. Figure 1 captures these findings. 
Figure 1. Agreement about the main motives, leverage factors and impacts of WPI according to three respondent groups (managers, employees, employee representatives)

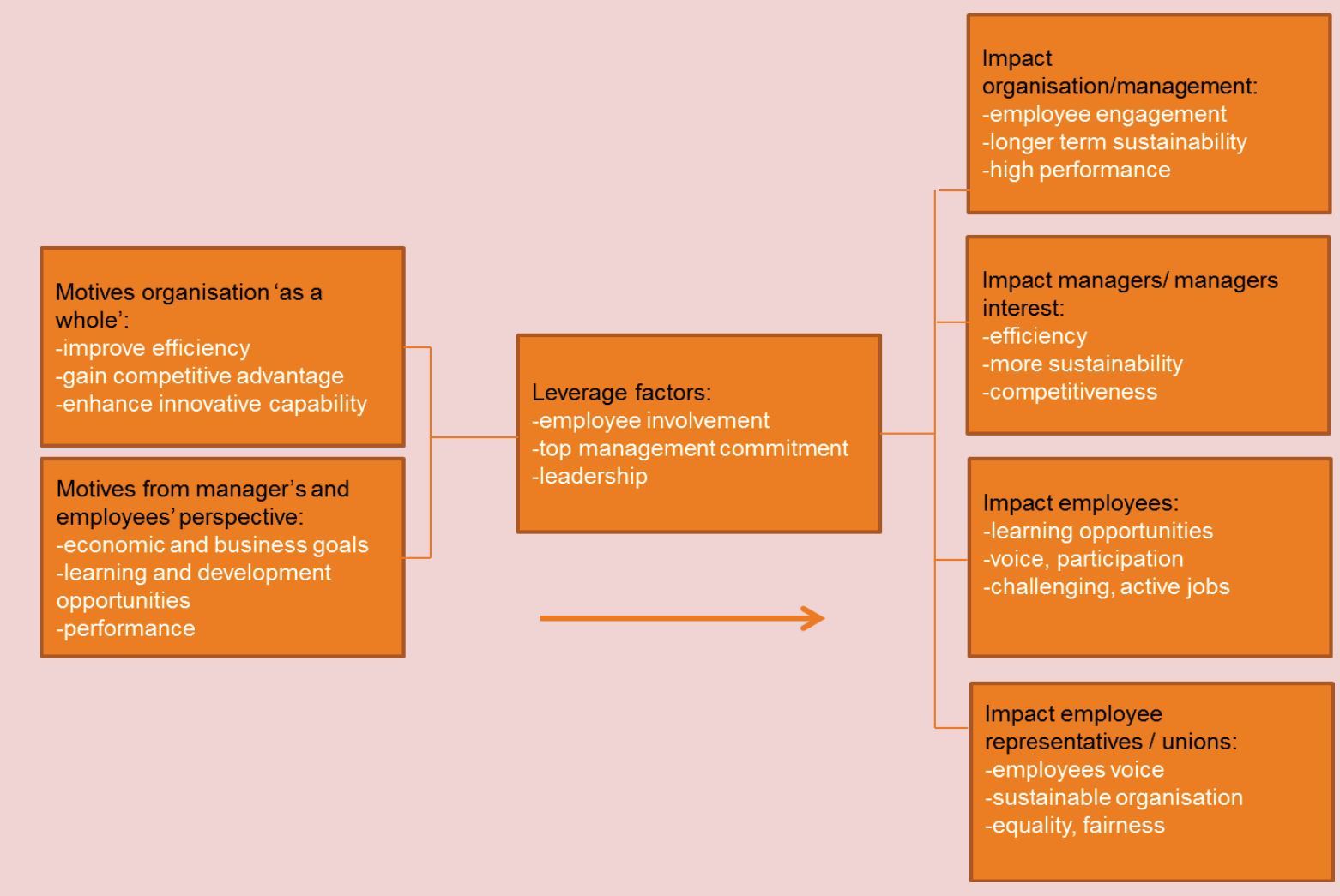

\subsection{How do companies implement} WPI?

Now we know what are the motives and leverage factors of WPI let us have a look at the 'how' issue. The process of initiation, adoption and implementation of WPI-practices reveals a common pattern. As described, companies chose paths that differ but conversely within companies there is agreement among managers, employees and employee representatives about why to introduce WPI, how to do it, and what impacts are desired. The research suggests that often the initiative for WPI lies with management, and that the main motive has an economic background. Once this decision is taken employees roll in to help design and implement the intervention. Consulting employee representatives is common among those companies who advocate communication and employee interests. Be reminded that our sample is from the top $5 \%$ of the ECS-database ranked according to the WPI-index score. Our 51 cases 
belong to those companies who score the highest on WPI. Many of these companies are WPI-mature and form the case studies we learned that they have often come this far after many years. The way that WPI-practices get implemented seems to reveal a generally applied pattern (Figure 2):

1. The initiative of a WPI often has an economic purpose (see 1 in Figure $2)$, although in many cases WPIpractices are not purely targeted at economic goals alone. Not seldom they are combined with or embedded in organisational, job and HR-related measures. Many WPI-practices are a combination of HR-related measures that on the one side may improve employee skills and competences, and on the other hand consist of appraisal and performance instruments. In short, where WPI-practices do aim at more than one goal there is almost always an economic purpose present and very often it is dominant.

2. Once the WPI-initiative is uplifted into a measure or set of measures employees - and often employee representatives - play an important role in (co-)designing and developing the WPI-practice and its implementation (see 2a the Figure 2). Management realises it is often impossible to get WPI implemented without the engagement of employees. In the first place the measure often deals with employees and their interests, and in the second place because management realises that employee participation is crucial for support and

Figure 2. Pattern of implementing WPI-practices (Oeij et al, 2015a: 59)

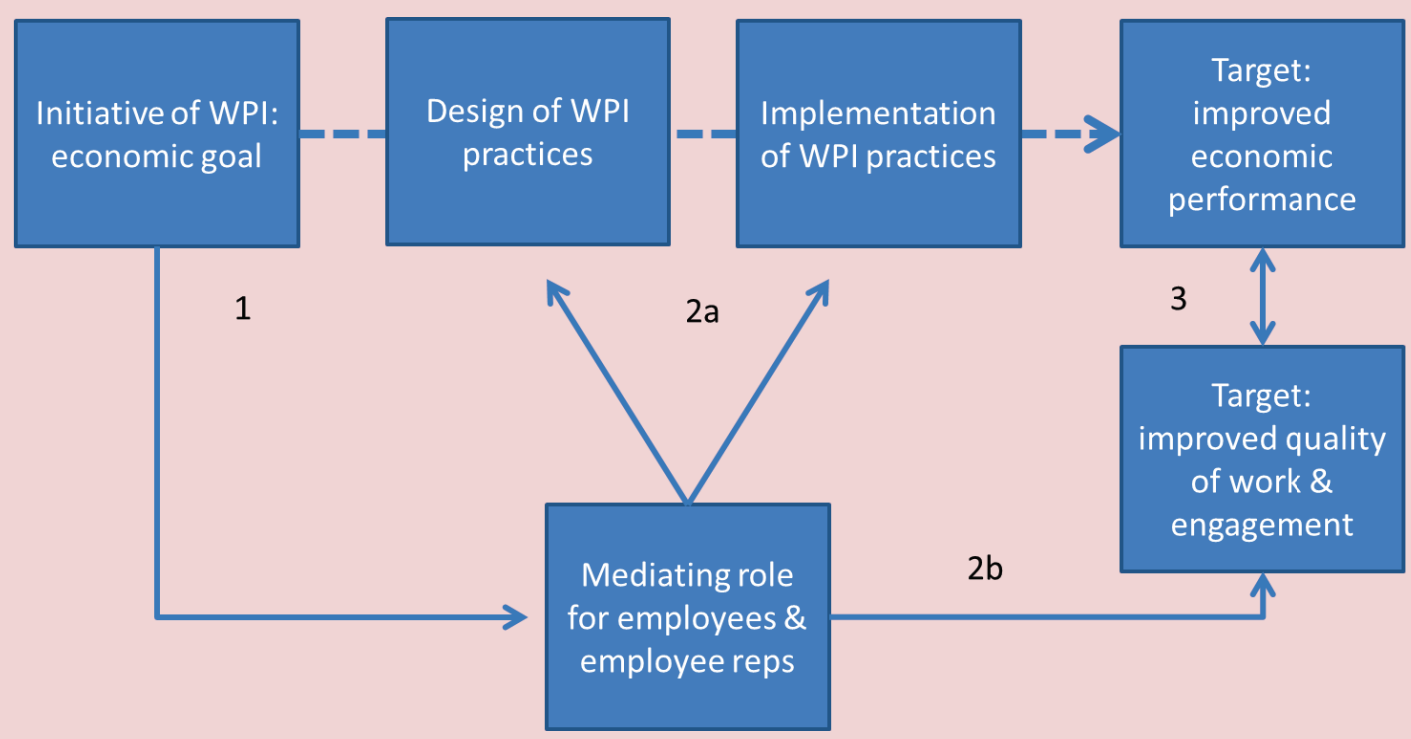


success. As employee participation in the design and implementation phase is inescapably connected to employee engagement and possibly improved quality of working life (as a result), there is an immediate link with employee-favourable targets (see 2a in Figure 2).

3. The target of improved economic performance is often not a direct effect of the implemented WPI-practice but in most cases influenced and supported ('mediated') by employees and employee representatives. When economic targets are achieved, it may well coincide with the target of improve quality of working life and employee engagement. Vice versa, an improved quality of working life and employee engagement can contribute to improved economic targets (see 3 in Figure 2).
Therefore it can be concluded that (initial) reasons and motives for WPI are mainly economic. Then, as a next phase, concrete WPI-practices are designed and implemented. Here, it becomes apparent that employees get to play a major role. The most important leverage factor for adoption and implementation is namely employee involvement. And again managers, employees and employee representatives seem to look through the same lens. Engagement of employees is a necessary condition for WPI. Other significant leverage factors are top management commitment and leadership.

\subsection{Examples of the process of} implementation

Companies adopt and implement WPI in their own specific way. Three examples from the United Kingdom,

Examples of the process of implementation:

\section{Leadership}

UK-ENER-ELEC-L: "We want this to be a business where views are listened to and where communications are open and honest. We also want this to be a workplace where positive ideas are encouraged and where achievements are celebrated" says the Head of HR. Open Forums replaced the previous company-wide meetings and suggestion schemes which had struggled to stimulate open and constructive dialogue and feedback. The CEO's open leadership creates trust and employees feel confident about the future. According to one employee: "It is interesting isn't it, you go to the Open Forums and people will say what they think and absolutely nobody will turn round and go, I can't believe he said that ... they might not agree with you but nobody will actually knock anyone for having a view because we are encouraged to have a view. That's really empowering I think." 


\section{Partnership with unions}

DK-SERV-PARK-S: Organisational changes are discussed by the manager and the union representatives. They have a partnership and value each other's opinions. The manager explains: "It is nice to have representatives who are not afraid to step up against me in a constructive dialogue". The implementation approach was that 1) management took initiative, 2) external consultants supported the process, 3) 'experiments' were conducted (a work gang tested new meeting practices or the like), 4) 'invitation' to the same knowledge for all (training) and 5) implementation of the practices, but not necessarily in the same way everywhere. No evaluation was done but adjustments were made along the way. Both management and employees believe that it is important to design the process in a manner that creates 'enthusiasts' amongst the employees. The union representative explains: "It gives a huge boost to the company that we work together to create a great workplace. ... That's what made us 'the best workplace' (a Danish award) in 2004". The employees believe that, even though management determines the direction, they have to have the trust to be able to discuss it: "It should be perfectly legal to say our outspoken opinion to our manager - and it is. There may well be disagreement, but you have to be able to discuss things" (employee).

\section{Dialogue with personnel}

LT-ACCOM-HOTELS-S: The WPI practice, Think Guest Feedback, consists of regular middle management meetings where middle managers from all departments (Front Office, Reservations, Conference Hall, Lobby, Restaurant, Sky Restaurant, Room Service, Marketing and others) regularly meet and review Hotel ratings in dedicated social media platforms. They discuss particular guest feedback cases and joint actions that could improve guest stay experience (and feedback as a result), together brainstorm on how guest feedback could be stimulated and collectively addressed, take important information back to the teams of their departments for further action, produce minutes of their observations and recommendations to top management on improvement of various hotel operational aspects and share experience with each other. Think Guest Feedback involves, for example, prompt reaction to guest feedback (especially when negative) before they leave the hotel, and constant organisational learning from any mistakes made. It implies staff empowerment, not only that they could solve emerging problems straight away, but that each of them could feel like owners of the business and be pro-active in preventing negative guest experiences. Mutual trust, goodwill and respect across departments (not to solve your own issues at other's costs) and between all levels of organisational management were stimulated. According to the Director General, the initiative is still very new, but after a few months, it is already showing benefits.

\section{Denmark and Lithuania give a} flavour of cultural differences (Oeij et al, 2015a: 53-54). From the UK an example is presented that shows how leadership enables employee participation, while the Danish example mirrors a stepwise approach that was agreed with unions. The Lithuanian case exemplifies the taking up of dialogue between management and employees, which is relatively new to the region. 
These examples show differences in the interplay between management, employees and their representatives. They agree in the sense that cooperation between actors is fundamental to improve the business.

\section{Conclusion and lessons for policy and practice}

The general view that emerges from the research can be captured in a few lines (Oeij et al, 2015a: 62). The initiative to start WPI practices comes from the management or ownership of the company. In only a minority of the studied companies does the first step come from the employees' side. However, these managers/owners have understood that the role and participation of the employees and their representatives is crucial for WPI to be a success and in the end for the companies' performance and sustainability. The reasons behind the management's decision to implement WPI practices are mainly related to efficiency, competitiveness and innovation enhancement. In a number of cases, the management decision to implement WPI is triggered by factors such as:

- a situation of crisis or difficulties in the company's performance that requires significant changes to survive and remain competitive in a changing and globalised market, where the traditional products/services and ways of working need to be revised and adapted in order to satisfy the requirements of increasingly exigent and sophisticated customers;

- sometimes, the former is also combined with a take-over from (or merger with) another (multinational) company which brings in new forms of work organisation and new work practices, systems, etc. that involve workplace innovation. In these cases there is a kind of 'WPI know-how transfer' from the headquarters to the subsidiary.

In several of the Eastern European case studies, the privatisation of public enterprises and the associated re-organisation processes have served as a background to the implementation of WPI, seeking greater efficiency and employee involvement that were previously lacking.

Factors related to job quality and good working conditions do not appear as primary reasons or motives for WPI, but more as a pre-condition or a result of WPI. This means that the objective of WPI introduction is not to improve the working conditions or the working environment as such, but that, in order to enhance employee involvement and their contribution to the company's performance and innovation processes, a good set of working conditions is required. 
The results are in line with economic research saying that 'organisation matters' to performance (Bloom and van Reenen, 2010) and with HPWPresearch that more or less shares similar opinions (Boxall, 2012). This implies that organisations can make strategic choices with their organisational structure. It seems beneficial to the emergence of WPI to strengthen the position of employees and employee representatives: this can help boost WPI-practices, which in turn may improve both economic performance and quality of working life.

\subsection{Some policy pointers}

Although workplace innovation has gained currency in Europe as a relevant boost to support the innovative capability of firms and organisations (see EUWIN, EUropean Workplace Innovation Network ${ }^{8}$, and for other initiatives see Chapters 3 and 4), more attention to improve workplaces is still needed. The reason for this is that the innovative capability can contribute to economic growth, high quality employment, adaptive capabilities and improved employment relationships, but we know that such improvement and innovation can no longer be built solely on economic, business model and technological innovation. Better use should be made of the human

\footnotetext{
8 http://ec.europa.eu/growth/industry/innovation/ policy/workplace/index_en.htm
}

potential to innovate and organize work processes: in short social innovation in the workplace (European Commission, August 2014). Several policy pointers are proposed in the Eurofound study Workplace innovation in European companies (Oeij et al, 2015a), but the most relevant pointers are directed at policymakers to help practitioners is to make WPI practical for them. Policy makers can do this in three ways. As a precondition they must urge to put the topic higher on the EU and national innovation agenda's, as technological and business innovation will need workplace innovation to make them successful and accepted. In the second place policy makers can improve business assistance programmes that help companies and organisations in the uptake of WPI-practices. Third, policy makers can stimulate to develop tools for companies, by which companies can diagnose their situation, develop their own WPI-practices, be supported in the process of implementation, and are enabled to evaluate the effects of their WPI-practices.

\subsection{Some pointers for practitioners}

WPI in our sample is supported by all actors in the companies: managers, employees and employee representatives. This clearly indicates good employment relationships and industrial relations among the company stakeholders, resulting in constructive 
cooperation, communication and collaboration, containing labour conflicts and seeking for common interests and goals. From the employer's side this requires management and leadership behaviours that not only bring the business forward but simultaneously stimulate trust and engagement of employees. From employees this demands entrepreneurial and intrapreneurial behaviours to apply their human talents in support of innovation, co-creating change and work motivation in general. From employee representatives and unions it asks for balancing the interests of employees, companies and themselves.

Choosing the right WPI-practices to implement is not an easy job. It requires to link an organisation's strategy to the management philosophy, and then to its structure and culture; and to do this while taking into account the viewpoints of management, employees and external stakeholders - unions, customers, etc. - at the same time. What do we mean by this? First, the management philosophy determines the strategy, in terms of achieving the organisation's goals top down or bottom up, to put it in a simplified way. That same philosophy is the basis for the design on the working processes, the structure. Again, one can choose a more top down versus a bottom up approach regards the division of labour and how to manage these working processes. That all boils down to the culture of an organisation if one looks at leadership styles and ways to engage employees, which can be more control oriented versus commitment oriented, depending on former choices. Eventually this will determine whether employees will be more pro-active or risk avoidant. Strategy, structure and culture together constitute a kind of causal link, or 'system' if one likes. Merely implementing employee friendly HR-measures, like innovation competitions, job performance interviews or company suggestion boxes that leave a top down structure intact, will therefore render more disappointment than satisfaction in the long run.

When developing WPI-practices one should take into account this 'root cause' character of the causal link. It is nonetheless hard to assess the impacts of WPI-practice of measures in advance, when one is designing such practices. Partly because it is hard to predict the outcomes, partly because how WPI-practices associate with other organisational factors is complex, and partly because some effects can be quantified, but many others cannot and remain 'qualitative' evaluations. To be able to build a 
proper 'business case' for such WPIpractices in which a trade-off can be made between quantitative and qualitative aspects, and by which the viewpoints of different stakeholders can be addressed, employers and employees can together apply a stepwise approach (Oeij, de Looze, ten Have, van Rhijn et al, 2012). In this approach employers and employees analyze the (future) productivity challenge and strategy of the organisation, and link this to possible workplace innovation practices, and its effects on performance and quality of work. By making a trade off between the advantages and disadvantages, applying a dialogue approach (Oeij, Wiezer, Elo, Nielsen et al, 2006: 258-259), they can build a solid business case for their final choice. The dialogue approach means that viewpoints from different perspectives are taken into account.

\subsection{Coda}

This contribution tried to make clear why leading WPI-companies apply WPI, how they implement it, and what are the impacts that they expect. WPI-mature companies have mature relations between management and employees, and often with employee representatives. These companies have built on such relations perhaps for many years. They understand that as stakeholders they need each other. We tried to underline the importance of the link between strategy, structure and culture and state these links can best be seen as a system. Chandler stated that 'structure follows strategy'. Not solely favouring limited linear thinking, we would like to add that culture follows strategy, and structure, as well. Workplace innovation thus requires a holistic or integral view on change.

\section{The authors and publisher gratefully acknowledge the following permission to use the material in this book:}

Oeij P.R.A., Dhondt S., Žiauberytė-Jakštienè R., Corral A., Preenen P. Implementing Workplace Innovation Across Europe; Why, How and What? In: European Work and Organisational Psychology in Practice. Special issue on Workplace Innovation (2017).

Oeij P.R.A., Dhondt S., Žiauberytė-Jakštienè R., Corral A., Preenen P. Implementing Workplace Innovation Across Europe; Why, How and What? In: Oeij P., Rus D., Pot F. (Eds.) Workplace Innovation - Theory, Research and Practice. Series "Aligning Perspectives on Health, Safety and Well-Being”. Springer Science+Business Media: Dordrecht, 2017. 


\section{References}

1. Achterbergh J., Vriens D. Organizations. Social systems conducting experiments. (2nd ed.; 1st ed. 2009). Berlin: Springer, 2010.

2. Bloom N., van Reenen J. Why do management practices differ across firms and countries? Journal of Economic Perspectives, 2010, no. 24 (1), pp. 203-224.

3. Boxall P. High-performance work systems: what, why, how and for whom? Asia Pacific Journal of Human Resources, 2012, no. 50, pp. 169-186.

4. Boxall P., Macky K. Research and theory on high-performance work systems: progressing the highinvolvement stream. Human Resource Management Journal, 2009, no. 19, pp. 3-23.

5. Christis J.H.P. Organization and job design: what is smart organizing? In: van Lieshout H.A.M., Polstra L., Christis J.H.P., Emans B.J.M. (Eds.). Management of labour. Societal and managerial perspectives. Groningen: Hanzehogeschool Groningen University of Applied Sciences, 2010. Pp. 39-71.

6. Dhondt S., Oeij P. Social innovation related to innovation in management studies. In: Howaldt J., Butzin A., Domanski D., Kaletka C. (Eds.). Theoretical approaches to social innovation - A critical literature review. Dortmund: SI-Drive [EU Seventh Framework Programme], 2014. September. Pp. 122-150. Available at: https://webgate.ec.europa.eu/socialinnovationeurope/en/magazine/ methods-and-tools/articles-reports/theoretical-approaches-social-innovation.

7. Dhondt S., Pot F.D., Kraan K.O. The importance of organizational level decision latitude for wellbeing and organizational commitment. Team Performance Management, 2014, no. 20 (7/8), pp. 307-327.

8. Dhondt S., Preenen P., Oeij P., Corral A., Isusi I., Totterdill P., Karanika-Murray M. European Company Survey: Construction of the Workplace Innovation Index and Selection of Companies. Leiden: TNO, 2014.

9. Dhondt S., van Hootegem G. Reshaping workplaces: Workplace innovation as designed by scientists and practitioners. European Journal of Workplace Innovation, 2015, no. 1 (1), pp. 17-25.

10. Eeckelaert L., Dhondt S., Oeij P., Pot F., Nicolescu G.I., Webster J., Elsler D. Review of workplace innovation and its relation with occupational safety and health: Literature review. Bilbao: European Agency for Safety and Health at Work, 2012.

11. Kankaraš M., van Houten G. Third European Company Survey 2013 - Overview report: Workplace practices - Patterns, performance and well-being. Luxembourg: Publications Office of the European Union, 2015.

12. Kesselring A., Blasy C., Scopetta A. Workplace Innovation. Concepts and indicators. Brussels: DG Enterprise and Industry, 2014.

13. Howaldt J., Oeij P.R.A., Dhondt S., Fruytier B. Workplace innovation and social innovation: an introduction. World Review of Entrepreneurship, Management and Sustainable Development, 2016, no.12 (1), pp. 1-12.

14. Kalmi P., Kauhanen A. Workplace innovations and employee outcomes: evidence from Finland. Industrial Relations: A Journal of Economy and Society, 2008, no. 47 (3), pp. 430-459.

15. MacDuffie J.P. The road to "root cause": Shop-floor problem-solving at three auto assembly plants. Management Science, 1997, no. 43 (4), pp. 479-502.

16. Oeij P., de Looze M., ten Have K., van Rhijn G., de Graaf B.. From Productivity Strategy to Business Case: Choosing a Cost-Effective Intervention for Workplace Innovations. JCC: The Business and Economics Research Journal, 2012, no. 5 (2), pp. 171-184.

17. Oeij P.R.A., Dhondt S., Korver, T. Social innovation, workplace innovation and social quality. International Journal of Social Quality, 2011, no. 1 (2), winter, pp. 31-49.

18. Oeij P., de Vroome E., Bolland A., Gründemann R., van Teeffelen L. Investing in workplace innovation pays off for SMEs: a regional innovation initiative from The Netherlands. International Journal of Social Quality, 2014, no. 4 (2), pp. 86-106. 
19. Oeij P.R.A., Wiezer N.M., Elo A.-L., Nielsen K., Vega S., Wetzstein A., Żołnierczyk D. Combating psychosocial risks in work organisations: Some European practices. In: McIntyre S., Houdmont J. (Eds.). Occupational health psychology: European perspectives on research, education and practice, 2006, vol. 1, pp. 233-263.

20. Oeij P., Žiauberytė-Jakštienè R., Dhondt S., Corral A., Totterdill P., Preenen P. Workplace Innovation in European companies. Study commissioned by Eurofound. Luxemburg: Office for Official Publications of the European Communities, 2015a.

21. Oeij P., Žiauberytė-Jakštienè R., Dhondt S., Corral A., Totterdill P., Preenen P. Workplace Innovation in European companies. Technical annex. Dublin: Eurofound, 2015b. Available at: https://www. eurofound.europa.eu/sites/default/files/ef1540_-_technical_annex_-_third_european_company_ survey_workplace_innovation_in_european_companies.pdf

22. Oeij P.R.A., Vaas F. Effect of workplace innovation on organisational performance and sickness absence. World Review of Entrepreneurship, Management and Sustainable Development, 2016, no. 12 (1), pp. 101-129.

23. Pot F.D. Workplace innovation for better jobs and performance. International Journal of Productivity and Performance Management, 2011, no. 60 (4), pp. 404-415.

24. Pot F., Dhondt S., Oeij P. Social innovation of work and employment. In: Franz H-W., Hochgerner J. (Eds.). Challenge Social Innovation. Berlin: Springer, 2012. Pp. 261-274.

25. Pot F., Totterdill P., Dhondt S. Workplace innovation: European policy and theoretical foundation. World Review of Entrepreneurship, Management and Sustainable Development, 2016, no. 12 (1), pp. 13-32.

26. Ramstad E. Promoting performance and the quality of working life simultaneously. International Journal of Productivity and Performance Management, 2009, no. 58 (5), pp. 423-436.

27. de Sitter L.U., den Hertog J.F., Dankbaar B. From Complex Organizations with Simple Jobs to Simple Organizations with Complex Jobs. Human Relations, 1997, no. 50 (6), pp. 497-534.

28. Totterdill P., Exton R. Defining workplace innovation: The Fifth Element. Strategic Direction, 2014, no. 30 (9), pp. 12-16.

\section{Information about the Authors}

P. R.A. Oeij - Senior Research Scientist, Consultant, TNO, Netherlands Organization for Applied Scientific Research (Schipholweg 77-89, 2316 ZL Leiden, The Netherlands, peter.oeij@tno.nl)

Steven Dhondt - Ph.D., Professor, Senior Research Scientist, Netherlands Organization for Applied Scientific Research (Schipholweg 77, 2316 ZL Leiden, The Netherlands, steven.dhondt@tno.nl)

Rita Žiauberytė-Jakštienė - Bachelor of Science, Junior Researcher, Netherlands Organization for Applied Scientific Research (Schipholweg 77-89, 2316 ZL, Leiden, The Netherlands, rita.ziauberytejakstiene@ tno.nl)

Antonio Corral - Bachelor of Economics and Business Studies, Master of Business Administration, Partner Director, IKEI Research and Consultancy (Parque Empresarial Zuatzu, Edificio Urumea, Planta $1^{\text {a }}$ E-20018 Donostia-San Sebastián, Gipuzkoa, Spain, acorral@ikei.es)

Peter Totterdill - Ph.D., Visiting Professor at Kingston University, London, Visiting Professor at Mykolas Romeris University, Vilnius; Director, Workplace Innovation Limited (54-56 High Pavement, Nottingham NG11HW, UK, peter.totterdill@ukwon.net)

Received August 29, 2016 